\title{
Sobre Juízes e Profissões: a Avaliação de um Campo Disciplinar Complexo
}

\author{
SANDRA CAPONI \\ FERNANDA REBELO**
}

\section{RESUMO}

A Saúde Coletiva é um espaço disciplinar complexo que reclama instâncias de avaliação capazes de reconhecer essa pluralidade de modelos e discursos que convergem na preocupação pela saúde das populações. Destacamos a incompatibilidade entre uma sobrevalorização de artigos publicados nas revistas de impacto, em sua ampla maioria de Biomedicina ou Epidemiologia, e a complexidade própria da área da Saúde Coletiva. Para questionar essa associação que atribui racionalidade e objetividade a um conhecimento, na medida em que é sancionado pelo uso (citações) da comunidade científica, utilizamos a distinção entre profissão e disciplina que Stephen Toulmin estabelece em A Compreensão Humana. A partir dessa distinção, nos perguntamos: "a forma de avaliação existente (autoridade profissional) contribui para defender as legítimas pretensões intelectuais de desenvolvimento da (disciplina) Saúde Coletiva?".

Palavras-chave: Saúde Coletiva; Ciências Sociais em Saúde; critérios de avaliação.

Recebido em: 02/05/2005.

Aprovado em: 12/05/2005. 


\section{A Complexidade do Campo Disciplinar}

Por muito tempo, diversos autores insistiram em afirmar que a Saúde Pública é um espaço disciplinar complexo, onde vários saberes e vários níveis de discurso coexistem e se confundem. Alguns (MINAYO et al., 2003.) destacam a necessidade de estabelecer diálogos mais frutíferos entre essas disciplinas, sendo que até hoje não parece existir um intercâmbio real que torne possível uma interação efetiva entre o campo das investigações epidemiológicas e as Ciências Sociais. Outros propõem dar continuidade aos estudos epidemiológicos, a partir de investigações etnográficas ou psicológicas das populações estudadas. Para outros, ainda, faz-se necessário estabelecer alianças entre estudos empíricos originários da Epidemiologia ou das Ciências Sociais com reflexões teóricas, ou históricas que nos permitam compreender a lógica dos modelos adotados, estabelecer demarcações entre conceitos, conhecer o modo como surgiram e se sucederam as teorias e os problemas próprios da Saúde Coletiva.

Pouco a pouco essas disciplinas tendem a se sobrepor, a auxiliar-se, a compartilhar métodos e modelos de investigação. Cada uma dessas alianças pode possibilitar uma melhor compreensão de problemas teóricos e práticos, tais como o controle e o combate de enfermidades emergentes e reemergentes, a distribuição de recursos escassos, o conhecimento da incidência e prevalência de diferentes doenças e a construção de ações efetivas para seu controle. A Saúde Coletiva é um desses poucos espaços de saber que nos permitem transitar pelos achados científicos - seus problemas e dificuldades - e, ao mesmo tempo, pela transformação desses conhecimentos em estratégias terapêuticas concretas, em políticas e programas de saúde. O nível dos discursos e os saberes, por um lado, e o nível das intervenções institucionais, por outro, aparecem aqui como as duas faces de uma mesma moeda.

Um olhar histórico sobre o modo como esses saberes e essas políticas foram edificadas nos permitirá delimitar melhor esse campo de estudo. Os desafios impostos pelos persistentes problemas de distribuição social das enfermidades podem ser mais bem compreendidos se observarmos as condições históricas que tornaram possível sua emergência, se atentarmos para o fato de que as dificuldades e conflitos que hoje existem podem ser repensados como efeito dos descobrimentos científicos e das eleições institucionais feitas no passado.

Mas a história da Saúde Pública não se limita à produção de conhecimentos nem às confrontações científicas, ou à multiplicação de estudos 
quantitativos; refere-se também aos diferentes modos como as sociedades pensaram e atuaram sobre os corpos dos indivíduos e as populações. Resulta então indispensável analisar não só as conquistas ou as polêmicas científicas, mas também a história das instituições e políticas públicas, considerando o modo como se vincularam no passado e como se vinculam no presente, a produção de discursos médicos, epidemiológicos e sociais com as intervenções institucionais.

A história das descobertas científicas ocupará, então, uma parte dentro desse espaço disciplinar complexo, onde, a partir do século XIX, entrelaçam-se os descobrimentos científicos, os estudos estatísticos referentes à natalidade e mortalidade, às políticas e instituições de assistência e prevenção das enfermidades, aos estudos demográficos e às estratégias de reorganização urbana, com a abordagem de fenômenos sociais pontuais e complexos, tais como o trabalho infantil, o alcoolismo ou a prostituição.

Se observarmos a Saúde Pública de uma perspectiva histórica, veremos que ela aparece como um espaço disciplinar privilegiado para compreender esse processo pelo qual as clássicas delimitações entre diversos campos científicos são redefinidas. Como afirma Lyotard, desde fins do século XIX, assistimos a um deslocamento da trama enciclopédica clássica: "disciplinas desaparecem, produzem-se usurpações das fronteiras das ciências, criando-se novos territórios" (LYOTARD, 1986, p. 75). Assim, parece que não deveríamos nos limitar a desejar que a Saúde Coletiva ingresse no espaço da interdisciplinaridade; pelo contrário, devemos assumir que ela está condenada a mover-se entre as fronteiras das ciências, gerando novos territórios de investigação e discursos.

A Saúde Coletiva é inevitavelmente interdisciplinar e é ali que aparecem os maiores desafios epistemológicos. É nesse espaço interdisciplinar que se deveriam situar as instâncias de avaliação para que possam contribuir com a excelência desse campo disciplinar. Parece necessário criar mecanismos capazes de avaliar essa diversidade de produtos e processos, reconhecendo, finalmente, a pluralidade de modelos que convergem numa preocupação comum: a saúde das populações.

No entanto, torna-se impossível falar de saúde das populações sem fazer referência à saúde dos corpos que as compõem. Será necessário então falar de dores e de sofrimentos, de doenças e epidemias, mas também de novas terapias, de remodelações nas intervenções médicas, da história dos achados 
científicos que possibilitaram uma radical transformação dos indicadores de saúde nos últimos 50 anos.

A Saúde Coletiva está diretamente vinculada às pesquisas médicas, aos estudos de laboratório, aos conhecimentos clínicos, aos conhecimentos derivados da anátomo-patologia e da fisiologia, mas não se limita a eles. De igual modo, está vinculada aos estudos estatísticos, às Ciências Sociais, e às Ciências Humanas, sem que possa ser reduzida nem à Epidemiologia, nem aos estudos qualitativos e às análises conceituais ou históricas.

A complexidade desse campo reclama certos cuidados e critérios complexos para poder avaliar a diversidade de produtos que surgem desse espaço de saber. Em primeiro lugar, porque não é possível limitar esses produtos à produção de artigos publicados, desconhecendo a existência da criação de planos de saúde, modelos de gestão, a avaliação de serviços, a elaboração de currículos que auxiliem a formação de recursos humanos em saúde. Muitos desses produtos, embora não se traduzam em papers de impacto, são instrumentos indispensáveis para alcançar o objetivo último da Saúde Coletiva que não se esgota na produção de conhecimentos como a Física ou a Química. Seu objetivo não é exclusivamente "representar", "medir", "calcular", ou "comparar", mas também "intervir", isto é, criar estratégias concretas que permitam otimizar os sistemas e serviços de saúde (HACKING, 1996).

\section{Profissão e Disciplina}

Esse campo disciplinar exige um modo de avaliação capaz de respeitar e compreender a diversidade de discursos, saberes e produtos. Assim, as dificuldades que encontramos quando nos referimos à avaliação de uma disciplina como a Física ou a Química parecem multiplicar-se quando referidos aos estudos dedicados à Saúde Coletiva.

Deixaremos de lado neste escrito a avaliação de produtos não publicados em periódicos ou livros. Iremos nos limitar à exigência, aceita por todos, de tornar público o conhecimento produzido, submetendo-o à crítica através da avaliação dos pares. Partimos da necessidade de expor os resultados das investigações à comunidade científica, seja através da participação em fóruns, congressos ou simpósios, seja através de livros ou publicações periódicas, de acordo com os critérios de avaliação dos comitês editoriais. Como afirma Popper (1989, p. 78): 
"A objetividade da ciência não é uma questão individual dos diversos cientistas, mas antes uma questão social da sua crítica recíproca, da divisão do trabalho, amistoso-hostil dos cientistas, da sua colaboração mas também das guerras entre eles".

Sabemos que, no momento de expor nosso trabalho à avaliação, devemos respeitar certa hierarquia estabelecida entre as publicações periódicas, capítulos e livros. Assim, deveremos dirigir nossa produção científica para as publicações que o sistema de avaliação considera como apropriadas e desconsiderar outras que o sistema avalia como não apropriadas. É aqui que começam os paradoxos e as dificuldades. Parte-se de uma certeza: as revistas com maior índice de impacto, aquelas que são mais citadas, pareceriam traduzir certa objetividade do campo de estudos; elas se apresentam como garantia de uma racionalidade científica compartilhada e aceita pela comunidade de pares que, ao valer-se das mesmas para produzir novos conhecimentos, legitima o universo que conhecemos com o nome pouco elegante de Qualis Internacional.

Entretanto, sob essa certeza se ocultam muitas dificuldades. Não desejamos repetir as reiteradas críticas ao pensamento único, nem nos refugiar na cômoda defesa do relativismo; porém deveremos nos perguntar de que racionalidade e de que objetividade se fala. Ou, dito de outro modo, que tipo de conhecimento é premiado e qual é condenado quando aceitamos sem questionamento uma hierarquia de saber em que "a mediana de impacto" parece ter-se transformado na medida do que deve ser considerado um conhecimento válido, objetivo e racional.

Quando aceitamos essa associação, parece que nos limitamos a sobrepor dois campos. Se admitirmos que o que confere racionalidade a um saber é a aceitação pelos pares (traduzida em publicações), estamos necessariamente identificando dois espaços que em princípio deveriam poder distinguir-se claramente: a disciplina (o conhecimento produzido) e a profissão (o conjunto de redes institucionais vinculadas com essa disciplina). Entretanto, é necessário reconhecer que uma e outra nem sempre caminham juntas, e para compreendêlas será necessário situá-las em perspectiva histórica.

Como a história da ciência mostrou, diversos conhecimentos, teorias e argumentos que hoje consideramos cientificamente válidos foram, no momento de ser enunciados, rejeitados ou simplesmente ignorados pela comunidade científica de pares. Sabemos também que muitas certezas proclamadas, referenciadas e 
defendidas pelas instituições e pelos profissionais de determinadas áreas do saber se mostraram posteriormente infrutíferas e, para poder serem abandonadas, tiveram que se opor à resistência das autoridades estabelecidas.

A pacífica convivência entre conhecimento científico e instituições estabelecidas parece limitar-se aos períodos que Kuhn (1971) chama de ciência normal, isto é, aos períodos nos quais predomina a reprodução de modelos e teorias aceitas que são aplicadas por deslocamento a diversos problemas mais ou menos próximos, sem grandes transformações ou inovações teóricas.

Para questionar essa rápida associação que nos permite atribuir racionalidade e objetividade a um conhecimento, na medida em que é sancionado pelo uso (citações) da comunidade científica, pode ser útil recordar a distinção entre profissão e disciplina que Stephen Toulmin (1977), um dos mais originais filósofos da ciência, estabelece em A Compreensão Humana.

Toulmin mostra até que ponto uma preocupação excessiva com o sistema lógico-matemático pode ser destrutiva para a compreensão histórica e reduzir nossa idéia de racionalidade, na medida em que nos faz esquecer que existe uma instância institucional e humana (profissional) que convive com a produção de conhecimentos científicos. Se o desenvolvimento científico tivesse dependido da aplicação de princípios fixos e universais a circunstâncias concretas, não seria necessário interrogar-se pela produção histórica e humana dos saberes. "Nesse caso seria possível formular critérios permanentes e sem ambigüidade da racionalidade científica que seriam os mesmos para todas as situações históricas e culturais" (TOULMIN, 1977, p. 268).

Nesse caso, as questões humanas, tais como a criação de instituições, as formas e rituais de avaliação, as regras de divulgação do saber etc. deveriam limitar-se a um problema: saber se esse grupo particular de cientistas aplicou os critérios universalmente aceitos. Ou, no caso contrário: que razões levaram esses cientistas a se extraviar e a não aplicar esses critérios?

\footnotetext{
"Mas, posto que já não há nenhuma base real para acreditar em tais critérios universais, mas existem muitas provas de que nossos critérios de eleição intelectual são significativamente variáveis, está opção já não pode ser considerada". (TOULMIN, 1977, p. 269).
}

Se descartarmos as pretensões de uma racionalidade universal, deveremos concluir que ela se vincula com sujeitos individuais cujas idéias e 
teorias são discutidas numa comunidade de especialistas, são aceitas ou rejeitadas, são avaliadas por comitês científicos, concorrem a prêmios e honras etc. O conhecimento científico não se esgota na crítica e substituição de conceitos, argumentos, teorias e problemas; ele se inscreve numa dimensão humana, que é a que configura a profissão e que, como toda instituição humana, está sujeita a lutas de poder, a grupos de pressão, a disputas entre associações, ou como diria Toulmin (1977, p. 272), "a partidos políticos e a golpes de Estado".

Um conceito ou teoria podem ser considerados "estabelecidos" só a partir do momento em que são levados a sério pelos membros influentes da profissão; por outro lado, uma inovação que o grupo de referência declara totalmente incorreta é como se não existisse, o que pode chegar a significar algo como a sentença de morte da teoria ou da carreira profissional do cientista. Estas afirmações de Toulmin nos convidam a considerar que a imagem que muitos cientistas têm de guardiões da objetividade precisa ser revista.

"Felizmente e de maneira mais realista, hoje já não estamos obrigados a supor que a conduta dos cientistas, quando estão agrupados em organizações profissionais, foge das leis gerais que governam as ações coletivas de outras instituições [...]. E posto que, na política acadêmica, o poder e a influência constituem os únicos valores livremente negociáveis, poderia argüir-se que a competência entre eles é ali mais intensa que em outros campos" (TOULMIN,1977, p. 273).

Devemos entender por profissão o conjunto de funções, sistemas de ascensão profissional, a estrutura das carreiras, prêmios e reconhecimento entre pares, agências de avaliação e fomento, rede de publicações reconhecidas, associações, simpósios, congressos e encontros, editoras especializadas. Esse pluralismo possibilita a existência de mudanças históricas nas profissões e permite que as autoridades instituídas possam estar submetidas à crítica. E assim como existem autoridades consagradas nas instituições universitárias, científicas ou doutas, existe também uma maioria de sujeitos menos autorizados ou reconhecidos, que operam de modo informal e que muitas vezes são obrigados a demonstrar perante seus pares sua adesão às normas estabelecidas. Afirma Toulmin (1977, p. 282):

"Eles devem demonstrar publicamente não só que dominam as normas de sua profissão, mas também que sua adesão a elas é total e absoluta, com um grau de exclusividade que em outros tempos só se exigia das ordens monásticas”. 
Toulmin está interessado em analisar até que ponto uma determinada estrutura profissional, suas autoridades e juízes podem contribuir para defender as legítimas pretensões intelectuais de desenvolvimento de uma disciplina. $\mathrm{Ou}$, dito de outro modo, que garantia existe para que uma profissão (instituição) e uma disciplina (conhecimento) caminhem juntas, com um mesmo objetivo, e até que ponto as normas estabelecidas pelas redes institucionais podem prejudicar o desenvolvimento satisfatório ou eficaz do conhecimento científico produzido nesse âmbito?

Voltemos agora ao nosso tema. Será que é possível, ainda reconhecendo que a profissão é uma soma de instâncias de poder e de aceitações quase monásticas das regras estabelecidas, imaginar que esta pode ser a doadora de racionalidade ao conhecimento científico produzido e divulgado?. Será que a estrutura de prêmios e castigos existentes para aqueles que aceitam as normas estabelecidas está destinada à criação de espaços disciplinares criativos, eficientes e críticos? Ao menos já não parece ser tão evidente como se supõe a correlação média de impacto/ objetividade científica.

Vejamos o que Toulmin (1977, p. 276) tem a dizer sobre a produção de artigos científicos. Se por uma parte ele reconhece que "os periódicos científicos estão entre as mais poderosas instituições de uma ciência", com seu peculiar espírito crítico dirá:

\footnotetext{
“A proliferação de periódicos e a aceleração das publicações são efeito, em parte, da fragmentação do saber e, em parte, da aguda competência por prioridade. Até poderia se sugerir que, ainda nos ramos mais originais da ciência, muitas vezes chegam à imprensa idéias antiquadas ou 'materiais prévios à publicação' que permitem garantir a prioridade de um autor sobre algum assunto" (TOULMIN, 1977, p. 280).
}

A afirmação, longe de diminuir o valor da produção científica veiculada em periódicos, permite-nos observar que nem sempre a convivência entre conhecimento científico e instituições estabelecidas pode garantir a produção de conhecimentos inovadores ou de excelência; permite-nos questionar o mecanismo de atribuição de racionalidade pela consideração exclusiva do impacto dos periódicos avaliados. 


\section{A Citação nos Diferentes Domínios do Saber}

As linhas editoriais estabelecem uma seleção daquilo que pode ser considerado como aceitável e aquilo que se considera inaceitável. Porém, tratase de uma distinção institucional e não epistemológica. Tomemos um exemplo: no mês de fevereiro de 2005, o Aesthetic Surgery Journal, publicação Qualis internacional $(\mathrm{B})^{1}$ publica um artigo com o título de "Continuing medical education article body contouring: Buttocks lifting”. Trata-se de um de muitos textos dedicados à mesma temática (técnicas para melhorar a aparência dos rostos e seios de jovens senhoras). Essa publicação, pouco relevante para a Saúde Pública, possui um peso consideravelmente maior que um capítulo de livro ou que um artigo específico da área publicada na revista Saúde em Debate (B Nacional), Physis (B Nacional) ou Ciência \& Saúde Coletiva (A Nacional).

Parece existir certa incompatibilidade entre uma sobrevalorização de artigos publicados nas revistas de impacto, em sua ampla maioria de Biomedicina ou Epidemiologia, e a complexidade própria da área da Saúde Coletiva. Se voltarmos a formular a pergunta "a autoridade profissional contribui ao desenvolvimento da disciplina?", é provável que encontremos diversas respostas dentro da área.

Para a Epidemiologia, as normas atuais podem significar um reconhecimento do modo como se produz o saber nessa área, que deve privilegiar as referências a estudos que estão sendo produzidos nesse momento, que precisa de uma rede de informação com outras pesquisas sobre temas afins, em que a integração de dados enunciados pelos pares resulta essencial para estabelecer comparações, para mostrar a relevância dos dados apresentados, para marcar as diferenças entre regiões e casos, assim como para justificar as posições defendidas pelo autor. Neste caso, a citação de publicações periódicas dos últimos anos deve integrar-se ao conhecimento produzido numa rede de diálogo que se retroalimenta, e sem a qual ele não seria possível.

Ainda que certos estudos de Sociologia empírica se movam na mesma direção, provavelmente será outra a posição adotada pelas Ciências Humanas que tentam trabalhar no marco da Saúde Coletiva. A análise de conceitos, teorias ou problemas específicos do âmbito da saúde, assim como o estudo das mudanças históricas ou culturais frente a uma epidemia ou a situações de violência, geralmente se valem das citações de outro modo. Aqui, as citações significam muitas vezes um recurso para autorizar os argumentos apresentados - neste caso se utilizam 
idéias defendidas em outros contextos por outros autores, preferencialmente clássicos, como forma de validação do discurso. Em geral, a rede de citações desses autores guarda mais dívidas com Durkeim, Weber ou Ian Hacking que com os últimos artigos publicados nas revistas de impacto.

Isto se refere à própria lógica da produção de conhecimento na área. Aqui não é necessário comparar os dados próprios com dados obtidos por outros. A rede de diálogo pode se estabelecer com autores que escreveram no século XIX, no século $\mathrm{V}$ antes de Cristo ou no último periódico da área. A referência de um artigo que remetia a Aristóteles pode ser evitada e servir como um convite para se voltar a ler a Ética a Nicomaco de outro ponto de vista. Se decidirmos referenciar esse artigo que nos levou a Aristóteles, será só para plasmar nossa gratidão ou dívida com esse autor ou por uma exigência ética, mas não será por uma exigência epistemológica. As citações ocupam um espaço diferente na produção de conhecimentos históricos, teóricos ou conceituais daquele que ocupam na epidemiologia e nas Ciências Biomédicas, a tal ponto que não é possível encontrar nenhuma referência à mediana de impacto nas áreas de Filosofia, História, Sociologia ou Antropologia.

Em certos casos, o conhecimento empírico produzido na área de Sociologia da Saúde ou de Antropologia Médica pode aproximar-se dos estudos epidemiológicos. Porém, mesmo que, em ambos os casos, se estabeleçam comparações entre dados que falam de diferenças regionais, étnicas ou sociais, a produção científica da área de Sociologia ou Antropologia não poderia ser hierarquizada de acordo com a média de impacto, pois esse é um critério originário das ciências duras - Química, Física, Biomedicina. Pelo contrário, não é a produção em periódicos, independentemente do impacto, mas sim a produção de livros o que se prioriza nas Ciências Humanas e Sociais. Quer dizer, cada área prioriza aquilo que constitui seu universo de diálogo, aquele veículo que considera uma ferramenta valiosa e imprescindível para construir seu conhecimento.

Neste caso, as instâncias de avaliação poderiam caminhar juntas com o desenvolvimento da disciplina. Entretanto, se pensarmos que a Saúde Coletiva não se esgota na Epidemiologia nem na Biomedicina, veremos que existe certa contradição entre as normas reconhecidas pelas instituições profissionais autorizadas e a produção de conhecimento nesse campo. E ainda que os nãoautorizados possam estar dispostos a aceitar religiosamente essas regras, corremos o risco de criar obstáculos para a excelência da área. 
Para compreender esse descompasso, será necessário recordar algo que acostumamos a repetir até o cansaço: que o conceito de saúde é muito mais complexo e amplo do que as Ciências Biomédicas acostumam imaginar. A saúde das populações é tão irredutível à Biomedicina e à Fisiologia, como estas o são à Física ou à Química. Então uma pergunta parece inevitável: por que razão nossos critérios de avaliação devem se identificar com os das Ciências Biomédicas ou com os critérios da Química e permanecer tão distantes dos critérios aceitos pelas Ciências Humanas e Sociais?

\section{Critérios de Avaliação nas Ciências Sociais e Humanas e na Saúde Coletiva}

Recordemos que, segundo a classificação da CAPES, a grande área da Saúde $^{2}$ engloba os seguintes programas: Educação Física, Enfermagem, Farmácia, Medicina I, Medicina II, Medicina III, Odontologia e Saúde Coletiva. Dentro da Saúde Coletiva são aceitos projetos vinculados a todas as áreas citadas acima, incluindo aquelas que não fazem parte da grande área da Saúde, mas com as quais a Saúde Coletiva possui estreito vínculo, como a Psicologia, o Serviço Social, a História, a Filosofia e a Antropologia.

Alguns programas de Saúde Pública/Coletiva contemplam linhas de pesquisa que debatem constantemente com as Ciências Sociais e Humanas como os trabalhos sobre biopolítica das populações, representações sociais, desigualdades étnicas e sociais, estudos sobre gênero e violência, bioética -, constituindo assim um campo interdisciplinar e não somente multidisciplinar ${ }^{3}$.

Se a Saúde Coletiva fosse um campo multidisciplinar, estariam resolvidos os grandes problemas da avaliação, como a necessidade de se publicar em revistas científicas com um alto índice de impacto. Esse critério de avaliação, que funciona muito bem no âmbito das ciências ditas duras, como a Química e a Física, e atende bem também à Epidemiologia, é desconsiderado quando se pretende analisar as publicações voltadas para as Ciências Sociais e Humanas.

O grande problema do critério de avaliação CAPES para a área de Saúde Coletiva é justamente ignorar sua interdisciplinaridade. O próprio comitê de avaliação para a área multidisciplinar diz:

"Cabe destacar que estarão sujeitas a uma avaliação desfavorável, no que concerne à classificação como interdisciplinar, propostas que apresentarem 
simples justaposição de duas ou mais áreas do conhecimento, constituírem uma reunião de pesquisadores que permaneçam trabalhando em compartimentos estanques, ou apresentarem grade curricular contendo disciplinas que cubram superficial e isoladamente diferentes assuntos, evidenciando formação enciclopédica"4.

Se respeitamos o critério definido pelo comitê multidisciplinar da CAPES (ver anexo), o critério de avaliação deveria atentar para o fato de que o uso da mediana de índice de impacto não é utilizado como critério de avaliação em nenhuma das áreas das Ciências Sociais e Humanas. Nas áreas de Filosofia, História, Sociologia e Antropologia, não existe qualquer referência ao JCR ou às exigências de publicações em Qualis A ou B. Estas só são exigidas aos programas de excelência, ou seja, aqueles que possuem nota 6 ou 7 .

Assim, os critérios utilizados não parecem atender à interdisciplinaridade própria da área. Ainda que esses critérios funcionem ao se avaliar a área de Epidemiologia, eles falham na avaliação dos estudos realizados nas áreas de Ciências Sociais e Humanas referidas à Saúde.

Comparando os critérios de avaliação da área de Sociologia, Filosofia e Antropologia com os de Saúde Coletiva, vemos a grande diferença, a começar pela avaliação dos periódicos. Para os periódicos de Sociologia, por exemplo, é necessário contar com conselho editorial; apresentar pelo menos uma indexação; publicar artigos de reconhecida relevância para a área (isto é, inovadores e atualizadores do debate científico internacional, nacional ou local); publicar autores de origens institucionais diversificadas; ter trajetória reconhecida e consolidada; apresentar regularidade de edição (ver anexo) ${ }^{5}$.

Assim, para atingir o conceito 4 nas Ciências Sociais e Humanas, além de ser reconhecida a produção de livros e capítulos de livros, não existe nenhuma referência a periódicos internacionais, centrando-se na produção de "periódicos nacionais de reconhecida qualidade científica com arbitragem de pares. Considerando-se fundamental a apresentação regular de trabalhos nos principais eventos científicos da área".

Já para a área de Saúde Coletiva, o JCR é adotado como referência base para a classificação dos periódicos de circulação internacional. $\mathrm{O}$ índice de impacto a ser utilizado é obtido a partir da mediana dos índices de impacto dos periódicos específicos de cada área. Assim, foi definido que os periódicos com fator de impacto igual ou superior à mediana da área serão classificados 
como Qualis Internacional A e abaixo serão classificados como Qualis Internacional $\mathrm{B}^{6}$.

Esse critério de avaliação da área de Saúde Coletiva é idêntico ao da Química: "Os veículos de publicação devem ser necessariamente indexados, preferencialmente em bases internacionais, e serão valorizados de acordo com os indicadores extraídos de bases de dados sobre citações, como o JCR/ISI" (ver anexo) $)^{7}$ e completamente diferente do das Ciências Humanas.

Mas, se deixamos de lado a preocupação pela mediana de impacto, veremos que os critérios utilizados pela Saúde Coletiva para atingir o conceito 4 ou 5 se aproximam dos requisitos exigidos na área de Filosofia para os programas de excelência, isto é, os programas 6 ou 7. Nesse caso, computa-se o percentual de docentes que tenham produzido, no triênio, pelo menos três publicações de nível A e/ou uma publicação de nível A internacional (sendo considerados como Qualis A livros que contenham contribuições teóricas significativas para a área), à semelhança das exigências da Saúde Coletiva para programas 4 ou 5. Ainda que na Saúde Coletiva se considere, para obter o conceito bom 4, o Qualis Nacional B e os Qualis Internacional C e B, na Filosofia, a produção internacional não é considerada uma exigência entre os artigos do triênio (utiliza a fórmula e/ou). Por outro lado, na Filosofia só fica especificado que, para atingir o nível 4 , será necessário possuir "produção docente e discente de boa qualidade" (ver anexo).

Ao se avaliar livros, artigos e atividades técnicas na Saúde Coletiva, achamos ainda mais dificuldades. Por exemplo, para a Sociologia, "a publicação de livros e capítulos é muito importante. A menção muito bom deve considerar o caráter nacional da distribuição da editora, bem como a sua importância em termos de títulos relevantes para a área". . Na Filosofia é considerada equivalente a periódico Qualis A (sob a condição da relevância para a área). Como vemos, são utilizados critérios bastante subjetivos - "a importância do título para a área", que "seja significativo" - não se levando em conta critérios quantitativos.

Para a Saúde Coletiva, ainda que um livro completo (com ISBN) corresponda a um artigo em periódico Qualis Nacional A e que um capítulo de livro corresponda a um artigo em periódico Qualis Nacional, a produção de livros e capítulos só pode ser avaliada e considerada no máximo de $25 \%$ da produção qualificada - ou seja, eles praticamente não têm nenhum peso na avaliação da produção científica. 
Outra contradição na avaliação diz respeito à não-consideração de trabalhos técnicos, visto que a área da Saúde Coletiva possui tradicionalmente um forte vínculo com a prática, como se pode ver através dos trabalhos de avaliação de programas e serviços, da elaboração de manuais técnicos e da participação na elaboração de planos de saúde, ao contrário do que ocorre na Antropologia, em que trabalhos técnicos, como a elaboração de laudos antropológicos, têm forte peso na avaliação.

Por outro lado, a participação em conferências, palestras no exterior, realização de eventos científicos, intercâmbios internacionais (não traduzidos em publicações Qualis), que não são considerados relevantes para a Saúde Coletiva, são estimulados e desejáveis para as Ciências Humanas e Sociais. Assim, na Sociologia, para se atingir o conceito 4, considera-se fundamental a apresentação regular de trabalhos nos principais eventos científicos da área.

Voltemos uma última vez à pergunta inicial: até que ponto a estrutura de avaliação pode contribuir para defender as legítimas pretensões intelectuais de desenvolvimento da Saúde Coletiva? Ou, dito com palavras do Toulmin, será que profissão (instituição) e disciplina (conhecimento) caminham juntas e compartilham um mesmo objetivo? Será que as normas estabelecidas pelas redes institucionais tendem a beneficiar ou podem prejudicar o bom desenvolvimento do conhecimento científico produzido no âmbito desse campo disciplinar complexo que é a Saúde Coletiva?

Analisando comparativamente os resultados da avaliação trienal 2001/ 2003, observamos que, de 26 cursos de Saúde Coletiva, 13 ficaram com notas abaixo de 4 - ou seja, insuficiente para se abrir o doutorado e correndo o risco de ter o mestrado fechado. Se talvez fossem consideradas as legítimas pretensões desse campo interdisciplinar complexo, outros critérios de avaliação poderiam vir a complementar o índice de impacto. Desse modo, poderíamos fortalecer uma área que parece ter ficado debilitada se comparada com outras. A abertura de doutorados, que é uma impossibilidade para os programas com conceito 3, significa não só uma melhor qualificação dos profissionais da área, mas também um fortalecimento dos núcleos e equipes de pesquisa, novas perspectivas institucionais e a possibilidade de se produzir conhecimentos de excelência.

Comparando os resultados da avaliação do triênio 2001/2003 da Saúde Coletiva com a Sociologia e a Antropologia, verificamos que, de 13 cursos de Antropologia, somente um ficou com nota abaixo de 4; e de 34 cursos de Sociologia, somente oito ficaram com nota abaixo de 4. Dos 44 cursos de Química, 
somente 12 ficaram com nota abaixo de 4. Pode-se afirmar que, desses cursos, três estão entre os recentemente criados; porém, o mesmo ocorre nas outras áreas. A dificuldade talvez possa ser encontrada analisando-se cuidadosamente os critérios de avaliação. Esses números parecem refletir que os critérios adotados pela CAPES não têm favorecido a área de Saúde Coletiva. Se considerarmos que a metade dos programas existentes só atingiu o conceito "regular", deveremos pensar que esta parece ser uma área disciplinar enfraquecida e não fortalecida pelas instâncias de avaliação existentes. Deixamos para outros a certeza de que o sistema de avaliação é o reflexo fiel de uma disciplina dividida entre aqueles cujos produtos alcançaram um estatuto epistemológico de racionalidade e objetividade (Qualis A) e aqueles que não o alcançaram.

\section{Considerações Finais}

Quando pensamos no poder conferido aos critérios de avaliação e classificação de periódicos na grande área da Saúde, não podemos evitar de recordar um texto publicado em 1748, por David Hume (1939). Em seu Ensaio sobre o Entendimento Humano, Hume escreveu um manifesto contra a metafísica, que mais tarde seria adotado como lema do positivismo lógico. Esse texto nos permite ironizar sobre os sistemas que hierarquizam os saberes, distribuindo-os em dois territórios: um válido e outro sem valor. Para Hume :

\footnotetext{
"Se procedêssemos a revisar as bibliotecas convencidos destes princípios, que estrago faríamos! Perguntemos sobre um volume: contém algum raciocínio sobre a quantidade ou o número? Não. Contém algum raciocínio experimental sobre questões de fato? Não. Atire-se então às chamas, pois não pode conter mais que sofisticação e ilusão" (HUME,1939, p. 689).
}

Hoje, parafraseando Hume, poderíamos perguntar: "esse volume está indexado no JCR, ou Medline ou Scielo? Não. Atire-o então às chamas, pois não pode conter mas que sofisticação e ilusão".

Para todos aqueles que preferem ler um livro a queimá-lo, vale pensar que aquilo que confere riqueza teórica e prática à Saúde Coletiva é a convivência dessa pluralidade de discursos, métodos e estratégias cognitivas que se referem à saúde das populações. Do diálogo entre especialistas de diversas áreas podem surgir mudanças políticas e institucionais capazes de contribuir para uma desejável transformação do precário equilíbrio existente no âmbito da saúde. 
Para isso será necessário desempenhar uma dupla função: ser ao mesmo tempo especialistas e intelectuais. Mas será necessário também que essa dupla função possa ser reconhecida e institucionalmente considerada como válida.

Como Susan Sontag soube mostrar, as duas funções não estão necessariamente sobrepostas:

"o intelectual livre é alguém que, além de sua competência profissional, técnica ou artística, tem o compromisso de exercitar e defender a vida da mente como tal. Um especialista também pode ser um intelectual. Mas um intelectual nunca é somente um especialista. Alguém é um intelectual porque tem (ou deveria ter) certos critérios de probidade e de responsabilidade no discurso. Esta é a contribuição indispensável dos intelectuais: uma noção de discurso que não é apenas instrumental, conformista" (SONTAG, 2005, p. 78).

Assim, ainda que como especialistas devamos aceitar as normas estabelecidas, como intelectuais cabe-nos iniciar um debate crítico sobre as mesmas; cabe-nos defender e exercitar a vida do espírito nos mais diversos foros, não só através da publicação dos resultados de investigações empíricas em revistas científicas, mas também através do desenvolvimento, possivelmente em livros ou capítulos de livros, de reflexões críticas relevantes para a área, sejam elas conceituais, históricas ou políticas.

\section{Referências}

HUME, D. Concerning human understanding. New York: The Modern Library, 1939.

HACKING, I. Representar e intervenir. México: Paidos, 1996.

KHUN, T. La Estructura de las Revoluciones Científicas. México: FCE, 1971.

LYOTARD, J. F. La Condición Postmoderna. Madri: Cátedra, 1986.

MINAYO, M. C. S. et al. Possibilidades e dificuldades nas relações entre Ciências Sociais e Epidemiologia. Ciência \& Saúde Coletiva, Rio de Janeiro, v. 8, n. 1, p. 97-107, 2003.

POPPER, K. A Lógica das Ciências Sociais. In: . Em busca de um mundo melhor. Lisboa: Fragmentos, 1989. 
SONTAG, S. Questão de ênfase. São Paulo: Companhia das Letras, 2005.

TOULMIN, S. A compreensão humana. Madri: Alianza, 1977.

On Judges and Professions: evaluation of a complex disciplinary field

Collective Health is a complex disciplinary field which demands evaluation mechanisms capable of recognizing this plurality of models and discourses converging in the concern over the health of populations. We highlight the incompatibility between overvaluing of articles published in high-impact journals, the vast majority of which in the fields of Biomedicine or Epidemiology, and the very complexity of the Collective Health field. To question this association ascribing rationality and objectivity to a form of knowledge on the basis of its sanctioning through use (citations) by the scientific community, we use the distinction between profession and discipline as established by Stephen Toulmin in Human Understanding. Based on this distinction, we ask: "Does the existing form of evaluation (professional authority) help defend the legitimate intellectual aims for development of Collective Health as a discipline?"

Key words: Collective Health; Social Sciences in Health; evaluation criteria. 


\section{CRITÉRIOS DE AVALIAÇÃO CAPES 2004 Anos-Base: 2001, 2002 e 2003}

\section{ÁREA ANTROPOLOGIA / ARQUEOLOGIA}

\section{1 - Nota 3}

A Comissão estabeleceu os seguintes critérios para um programa nota 3:

\section{Corpo Docente}

O corpo docente dos cursos de Pós-Graduação em Antropologia deve ser constituído, em sua totalidade, por professores/pesquisadores doutores. O curso deve contemplar um núcleo básico de no mínimo 7 professores com dedicação exclusiva à universidade, dos quais pelo menos 5 tenham o Programa como atividade principal. Todos os docentes permanentes devem realizar atividades de ensino e orientação na graduação (quando existir), além daquelas desenvolvidas no programa de pós-graduação. A produção intelectual dos docentes deve refletir os resultados de pesquisas realizadas e precisa articularse às linhas de pesquisa. A participação de alguns docentes em tarefas de natureza administrativa (coordenação de cursos e chefia de departamento) ou representativa (participação em conselhos acadêmicos) será considerada como um fator positivo.

\section{Atividades de Pesquisa}

As linhas, núcleos ou eixos de pesquisa devem ser bem definidos, visíveis, abrangentes, em quantidade e diversidade suficiente para se adequar às especialidades dos docentes e abranger diversos temas da Antropologia. É importante haver coerência entre as áreas de concentração, linhas de pesquisa e 
estrutura curricular. As atividades de pesquisa devem envolver alunos de graduação e pós-graduação, resultando em produção intelectual docente e discente.

\section{2 - Nota 4}

Para obter uma nota 4, o Programa deve contemplar, além dos critérios definidos para nota 3 , os seguintes aspectos:

\section{Corpo Docente}

Possuir um corpo docente estável, permanente e comprometido em tempo integral. Valorizar a presença e a participação de professores visitantes, em sintonia com a proposta e objetivos do curso. No entanto, a presença de professores visitantes não deve ser utilizada para sanar deficiências do núcleo permanente.

\section{Atividades de Formação}

A estrutura curricular deve apresentar um elenco de disciplinas optativas que possibilitem, além de uma sólida formação nas áreas básicas, opções que atendam aos interesses diversificados dos alunos. A relação orientador/ orientando deve ser distribuída proporcionalmente entre os membros do corpo docente. Os orientadores de doutorado devem possuir significativa experiência anterior na orientação de dissertações de mestrado e ter uma sólida e regular produção intelectual em veículos de qualidade reconhecida no Qualis da área.

\section{Produção Acadêmica Docente}

Deve ser estável e bem distribuída entre os docentes, incluindo livros, capítulos de livros e artigos em periódicos nacionais de reconhecida qualidade científica com arbitragem de pares. Considera-se fundamental a apresentação regular de trabalhos nos principais eventos científicos da área.

\section{3 - Nota 5}

Para obter a nota 5, o Programa deve, além dos critérios definidos para nota 4, obter: 


\section{Programa}

O Programa deve organizar, ao longo do triênio, ao menos um evento que envolva a participação de pesquisadores de outras instituições do país. Deve também ter uma publicação regular (periódico, boletim, série, etc.). A instituição-sede do Programa deve possuir uma biblioteca que contenha os clássicos das Ciências Sociais e áreas afins, assim como um amplo acervo das principais obras contemporâneas e coleções e/ou assinaturas dos periódicos nacionais e internacionais mais relevantes.

\section{Corpo Docente}

Deve possuir uma composição equilibrada no que diz respeito ao tempo de titulação e instituições de formação (doutorado). Deve ser valorizada também a participação dos docentes (cerca de 10 a $15 \%$ dos permanentes) em diferentes formas de estágio inter-institucionais de formação nacionais e internacionais, entre elas o pós-doutorado. Será considerada a participação dos docentes em cargos de representação em associações científicas e órgãos de fomento à pesquisa. Será levada em conta a participação dos docentes em atividades de consultoria técnico-científica (editorias e comissões editoriais, pareceres ad hoc, laudos e perícias etc.). Será apreciada positivamente a presença dos docentes em atividades de outros Programas de Pós-graduação no país (bancas, palestras, cursos, co-orientações etc.). É indispensável que todos os docentes do NRD6 publiquem ao longo do triênio, em veículos de reconhecida qualidade. É salutar que o Programa receba regularmente professores visitantes e/ou recém-doutores.

\section{ÁREA SOCIOLOGIA}

Nível 3: Programa em processo de consolidação ou programa já consolidado mas de alcance local. Atende aos requisitos mínimos de capacitação dos docentes, com linhas de pesquisa em funcionamento e produção científica que já ganha visibilidade em publicações e fóruns da área de Sociologia. 
Nível 4: Programa bem constituído, consolidado, com boa produção científica relacionada às linhas de pesquisa, e fluxo regular de alunos. Tem alcance regional e seus docentes ocupam lugar importante nos fóruns da área. Os resultados de pesquisa são divulgados regularmente em bons veículos da área.

Nível 5: Programa de alcance nacional e mesmo internacional. Constitui liderança científica na área de Sociologia. Congrega docentes de reconhecida importância e produz ativamente por meio de linhas de pesquisa que incluem os temas mais inovadores da área. Os resultados das pesquisas, tanto de docentes como de discentes, são publicados nos melhores veículos, o que inclui artigos de periódicos de elevada classificação e livros de editoras de prestígio e ampla distribuição.

Níveis 6 e 7: Programa com as características do nível 5, e que pode ser considerado como comparável aos melhores programas de instituições estrangeiras. O programa mantém estreita relação de cooperação com reconhecidas instituições de outros países. Seus docentes apresentam elevado grau de atividades de pesquisa, publicação, ensino e organização de eventos de caráter internacional. Um programa de nível 6 conta com cerca de metade dos docentes desempenhando atividades acadêmicas de natureza internacional. Para programa de nível 7, essa exigência eleva-se a dois terços dos docentes.

\section{FILOSOFIA/TEOLOGIA - SUBCOMISSÃO FILOSOFIA}

Programa de nível 3 satisfaz cumulativamente as seguintes condições: possui a maioria de docentes no NRD-6, bem qualificados ou em processo de qualificação; área de concentração e linhas de pesquisa bem estabelecidas, com projetos adequadamente vinculados às mesmas, e produção docente regular, em termos de qualidade e periodicidade (média de pelo menos três artigos por docente no triênio, divulgados em veículo classificado no Qualis/nacional). O programa deve demonstrar perspectivas de progresso e capacidade de investimento, visando a ascender a níveis mais altos. 
Programa de nível 4 deve apresentar todas as características de um programa nível 3 e, além delas, estar claramente consolidado. Isso deve se traduzir em $70 \%$ das atividades de orientação, ensino e pesquisa a cargo do NRD 6, com produção docente e discente de boa qualidade.

Programa de nível 5 é considerado de excelência na área. Apresenta corpo docente muito bem qualificado, com $80 \%$ das atividades de orientação, ensino e pesquisa a cargo do NRD 6, tradição acadêmica, produção docente e discente de qualidade, sendo um programa fortemente consolidado e demonstrando boas perspectivas para o futuro.

\section{ÁREA DE QUÍMICA}

Os veículos de publicação devem ser necessariamente indexados, preferencialmente em bases internacionais, e serão valorizados de acordo com os indicadores extraídos de bases de dados sobre citações, como o JCR/ISI. Serão considerados internacionais somente periódicos com índice de impacto igual ou superior a 0,07 no JCR. De acordo com esses índices, serão classificados como internacional A(IA) periódicos com índice de impacto igual ou superior a 1, como internacional B (IB) os com índice de impacto inferior a 1 mas igual ou superior a 0,5 , e como internacional $C$ (IC), aqueles com índice de impacto menor que 0,5 , mas igual ou superior a 0,07 . Periódicos nacionais serão considerados quando indexados em alguma base nacional ou internacional. O periódico Anais da Academia Brasileira de Ciências, com índice de impacto ainda não mensurado, mas com corpo editorial internacional, será classificados como nacional A (NA). Outros periódicos indexados no Scielo, ou outra base nacional, serão considerado como nacional C (NC). 


\section{GRANDE ÁREA DA SAÚDE}

CONCEITO 4: 80\% ou mais dos docentes NRD6 tenham publicado no triênio o mínimo de três artigos/docente em periódicos classificados como Qualis Nacional B ou superior. Nessa produção intelectual deve existir pelo menos um artigo/docente/triênio em Qualis Internacional C ou superior. Exemplo: programa com 10 docentes NRD-6 oito docentes NRD6 deverão ter publicado no mínimo 24 artigos em periódicos Qualis Nacional B ou superior, sendo que devem existir pelo menos 10 artigos em periódicos Qualis Internacional C ou superior.

CONCEITO 5: 80\% ou mais dos docentes NRD6 deverão ter publicado no triênio pelo menos 03 artigos/docente em periódicos classificados como Qualis Nacional A ou superior. Nessa produção intelectual deve existir pelo menos um artigo/docenteNRD-6/triênio em Qualis Internacional A ou B. Exemplo: Programa com 10 docentes: oito docentes NRD-6 deverão ter publicado no mínimo 24 artigos em periódicos Qualis Nacional A ou superior, sendo que devem existir pelo menos 10 artigos em Qualis Internacional A ou B.

\section{COMITÊ MULTIDISCIPLINAR / INTERDISCIPLINAR CAPES}

\section{Características de um Programa Interdisciplinar}

Um programa interdisciplinar deve se caracterizar por uma proposta integradora com áreas de concentração indicando objetivos focalizados. O corpo docente deve ter uma formação disciplinar diversificada mas coerente com as áreas de concentração, linhas ou projetos de pesquisa integradores. A grade curricular deve ser apropriada à formação dos alunos, constituída por um conjunto de disciplinas coerentes com as áreas de concentração, evidenciando a construção de linhas de pesquisa integradas. O corpo docente deve apresentar experiência, competência e produtividade cientifica nas respectivas disciplinas de origem, respeitando os parâmetros de produção acadêmica específicos de cada uma dessas das áreas; seria ideal que esses pesquisadores possuíssem alguma experiência em pesquisa multidisciplinar. Cabe destacar que estarão 
sujeitas a uma avaliação desfavorável, no que concerne à classificação como interdisciplinar, propostas que apresentarem simples agregação de duas ou mais áreas de conhecimento para examinar um mesmo tema sob pontos de vista distintos. O corpo docente deve apresentar experiência, competência e produtividade científica nas respectivas disciplinas de origem, respeitando os parâmetros de produção acadêmica específicos de cada uma dessas das áreas; seria ideal que esses pesquisadores possuam alguma experiência em pesquisa multidisciplinar.

\section{NOTAS}

* Doutora em Filosofia pela Universidade Estadual de Campinas, em 1993; professora do Departamento de Saúde Pública da Universidade Federal de Santa Catarina. Endereço eletrônico: sadracaponi@newsite.com.br.

** Mestre em Saúde Pública pela Universidade Federal de Santa Catarina. Endereço eletrônico: feferebelo@yahoo.com.br.

${ }^{1}$ A revista referenciada é Qualis Internacional B para Medicina I. A área utiliza os Qualis das áreas que a compõem para classificação das revistas que não estão nas bases da área específica.

${ }^{2}$ www.capes.gov.br - Avaliação 2003.

3 . De acordo com os critérios da CAPES, campo interdisciplinar é aquele onde há convergência de várias áreas de conhecimento não pertencentes à mesma classe, gerando novos conhecimentos e um novo perfil de profissional. Já multidisciplinar é o programa que agrega diversas áreas ao redor de um ou mais temas, mas no qual cada área preserva sua metodologia, não necessitando do conhecimento das outras áreas para o seu desenvolvimento. Ver: www.capes.gov.br - Critérios de avaliação multidisciplinar.

${ }^{4}$ Idem.

${ }^{5}$ Critérios de avaliação da área de Sociologia.

${ }^{6}$ Critérios de avaliação da grande área da Saúde.

${ }^{7}$ Critérios de avaliação da área de Química.

${ }^{8}$ Critérios de avaliação da área de Sociologia. 